\title{
The Perceived Factors of Student Suicide in Fiji
}

\section{Rosalie Muertigue* and Kamala Naiker}

Department of Social Science, University of Fiji, Fiji

\begin{abstract}
Teenage suicide rate in Fiji is increasing every year. This paper examined on the factors that lead to students' suicide in Fiji as well as the school's roles in preventing suicide attempts. Based on this study, the researchers found out various causes of student suicide in Fiji. Parents and teachers are involved in curbing this problem. Several factors that cause student suicide are identified during data gathering. A structured questionnaire was distributed to the 20 participants of the University of Fiji. The study can help guide the development of campus-based prevention programs at the university.
\end{abstract}

\section{Keywords: Suicide; Social, Emotion; Memory}

\section{Introduction}

Suicide is one of the principle causes of death among students. Current reports have advocated that the occurrence of suicide in this group increased in recent years. Hence, university grounds stand for a noteworthy location of intervention for the avoidance of suicide for scores of young adults [1]. University institutions and teachers on university campuses nowadays are frequently confused as to the paramount way to deal with suicidal scholars. Suicide among university learners is a predicament of multifaceted features that affects survivors, educators, establishments and parents. In a research carried out in Delhi, the formation of suicidal ideas among adolescents was found to be at a rate of $21.7 \%$ [2]. Authors emphasised the urgency to deeply understand the reasons for suicide cases [3,4]. Dogra, et al. found that other than stressful life events, there were other predictable variables [5]. Individuality, the meaning of life, and the reasons for living contribute considerably to suicidal concepts. It is noteworthy that features associated with suicide risk factors, like a feeling of hopelessness and loneliness in life, have received considerable study [6]. But in recent years, studies that place a greater emphasis on factors, like the reasons for living, are escalating anxiety. Current researches exposed that reasons for the notion of living is important to a person's mental processes of awareness, memory, decision making, and way of thinking, and is in juxtaposition relating to a person's emotions and the power to choose or to determine. Minkoff state that, according to cognitive theory, suicide is sought by a person as a final resort, to end or finally deal with thoughts or feelings of depression and misery [7]. If a person is full of depression, with nothing to live for, suicidal dangers increase drastically. The focal aspect needs also to be on the negative hindsight, rather than only on the positive and preventive aspect of suicide, which seems to be the current focus.

Suicidal ideation is a thought or hypothesis enclosing a range of theoretical constituents, characteristically one believed to be biased and not supported on experiential confirmation concerning bereavement, suicide and grave self-harming deportments, and consists of contemplation connected to the preparation, behaviour and result of suicidal conduct, predominantly as the last communicates to the opinions about a reaction of others [8]. According to Bonner and Rich, and Fawcett the considerations and the mental action of acquiring knowledge and understanding through thought, experience, and the senses about the suicidal way, in which one does something or conducts oneself, especially toward others, as well as one's intent, may be judged as a premature indicator for the danger of further severe suicidal behaviour patterns. The ideas or concepts of suicidal behaviour have also been observed as a fundamental part in the categorization of suicidal behaviour patterns. There are different ranges of harshness when dealing with suicidal ideation. These can be distinguished as ranging from moderately mild to general thoughts and wishes for death, to severe ideation about precise preparations and ways of taking one's life. Suicidal individuals' concerns regarding other's reactions to them, including others' perceptions of their self-worth after their death, are acquiring understanding through the thoughts, the experiences, and the senses that are inside this sphere. Reasons, both positive and negative, for living ideals help in avoiding suicidal behaviour. This study is an intention to highlight, and has been taken to learn the occurrences inducing suicidal ideation, its regularity and the affiliation between suicidal ideation and motives for existing among college students. In particular, the hypotheses are:

1. Life occurrences inducing suicidal thought differ among themselves.

\section{Reasons for existing are negatively related with suicidal ideation.}

Youth suicidal behaviour is one urgent challenge confronting our nation's colleges. At a national level, this persists to be an important communal well-being crisis in need of attention [4]. It is often the moral right and officially permitted responsibility of the University Student Counsellor, whenever possible, to prevent youth suicide [9]. The counsellors' reports are ill prepared, and frequently indicate their incapability to respond to this concern [10]. This is a matter of life and death, given the manner in which such issues are tackled by the college counsellors and other college-based practitioners. Well-trained and knowledgeable practitioners will be able to identify the suicidal signs, and with proper counselling, nip such tendencies in the bud before a disaster results. A valuable life is saved.

\section{Statement of the Problem}

This research study will focus on the perception of the students in University of Fiji regarding the prevalence of students' suicide in Fiji, and the school's roles in preventing suicide attempts.

*Corresponding author: Rosalie M, Department of Social Science, University of Fiji, Fiji, Tel: +679 664 0600; E-mail: rosaliep@unifiji.ac.fj

Received April 05, 2018; Accepted April 26, 2018; Published May 02, 2018

Citation: Muertigue R, Naiker K (2018) The Perceived Factors of Student Suicide in Fiji. Arts Social Sci J 9: 359. doi: 10.4172/2151-6200.1000359

Copyright: (c) 2018 Muertigue R, et al. This is an open-access article distributed under the terms of the Creative Commons Attribution License, which permits unrestricted use, distribution, and reproduction in any medium, provided the original author and source are credited. 
Specifically, it will try to answer the following questions:

1. What are the perceived reasons of student suicide in Fiji?

2. What are the characteristics of a suicidal student?

3. What are the school's roles in preventing student's suicide attempts?

\section{Purpose of the study}

The purpose of this case study is to identify the various factors that lead to student suicides, and determine the different roles of the school in preventing suicide attempts. This study is a pioneering research in the University of Fiji. The study can help guide the development of campus-based prevention programs at the university. This research study hopes to understand critically the factors of student problems in Fiji, and the school's corresponding roles in preventing suicide attempts.

\section{Methodology}

\section{Research design}

In this study, a case study method was utilized, in which the researcher investigates a real-life, bounded system over time, through in-depth data collection [11]. Yin stressed out that "case study research involves study in a real life context or setting" (p. 9). A semi-structured questionnaire was prepared to serve as a guide during the face-to-face interview with the respondents.

\section{Research instrument}

The researcher prepares a modified questionnaire from Suicidal Ideation Questionnaire Reynolds, investigating on the reasons why a student commits suicide, and finds better ways to prevent the student from committing suicide. The questionnaire is a combination of closed-ended questions and open-ended questions. The primary aim of the question is to obtain a qualitative data on the causes of the student's suicide problems, based on the student's perception.

\section{Ethical consideration}

Since the study utilized human participants and investigated the causes of students' suicide, certain issues were addressed. The consideration of these issues is necessary for the purpose of ensuring privacy, as well as the security of the participants. These issues were identified in advance, so as to prevent future problems that could have risen during the research process. Privacy, anonymity, and consent of the participants were the significant issues that were considered.

\section{Respondents and sampling}

This study is a school-based research conducted to the students of University of Fiji. Twenty students are chosen from different schools, using the convenience sampling method. The researcher opted to use this kind of research, considering the desire of the researcher to obtain first-hand data from the respondents, in order to formulate rational and sound conclusions and recommendations of the study.

\section{Results and Discussion}

\section{Respondent's perception on suicide based on age and gender}

University life is a time to move into adulthood, and this can be hard on some students who cannot cope with the academic demand, the financial problems, and the social strain, which can lead to social issues that can affect the immune system of person. Stress from academic course loads and the high demand expected from university level students serve as the leading contributing factor to development of depression with suicidal thoughts. In some societies, committing suicide is abnormal, especially in Fiji; however, in the Far East, a Buddhist priest who commits suicide as a form of political protest, is regarded as exhibiting strength of character, or in Japan, where harakiri is a sign of chivalry. This study will explore deeper on the reasons why students commit suicide, and examine the school's roles in preventing suicide based on the perspective of the students in the University of Fiji.

Suicide is the third leading cause of death for adolescents 15 to 19 years old. According to Medical Doctor Alan Glass, depression and suicide are the largest health issues facing college students nowadays. Based on the survey results, majority of them are fully aware on the increasing cases of student suicides in Fiji. There are many questions that come across on the issue of student suicides. Who are to be blamed, the parents or the teachers? Is it social media, or peer pressure? Psychologist Randy Dellom explained that "teens commit suicide because they feel extremely lonely, desperate and helpless. They strongly believe that taking their lives is the only solution to their problems. In this study, majority of the respondents stated that the age 19-21 years old is when most of the students commit suicide, and 30 percent of the respondents perceived the age of 16-18 years as also when most student suicides occur. This is the stage where students are more prone to commit suicide, as they are entering their maturity age, and more exposed to relationship problems and hardships in life. Psychologist Erik Erikson describes this stage as most critical, because an adolescent may experience a psychological revolution [12]. They try many roles as they grope with romantic involvement, vocational choice, and adult statuses. In this study, girls are more likely to commit suicide than boys. Based on some research studies, women are especially prone to psychological problems, such as depression, which almost always precede suicide. It was found out that in Western societies, women have a higher rate of 20 to 40 percent of mental disorders than males. According to respondents' perceptions, girls have higher risk of committing suicide than boys. The study of Lie $\mathrm{H}$ supports this finding that female students are highly to consider suicide, compared to male students [13]. Women are more likely than men to attribute suicidal ideation to negative relationship events. Perceived causes of suicide in Fiji were similar and distinct compared to UK and New Zealand. Men and women have different suicide methods to end their life.

\section{Reasons of suicide in Fiji}

This study identified three major reasons of suicide as perceived by the respondents: financial problems, family issues and relationship issues. Many students suffering from financial problems commit suicide. Students who are out on their own for the very first time could hardly manage their school allowance. They end up overspending on clothes, food and partying. The Community Mental Health Journal found out that the increased financial difficulties facing college students lead to greater depression, anxiety, and alcohol misuse over time. The researchers found out those family issues will also lead the students to commit suicide, like in instances where some students are abused verbally and physically by their parents. Family disagreements and lack of understanding among family members is an issue that needs to be resolved. The introduction to external examination in schools has built a lot of tensions and conflicts among students in Fiji. Almost all parents want the best for their children, and they put intense pressure on their children to get good grades. Some parents are unaware that too much pressure can lead to stress and anxiety. According to psychologist Ben Locke, of Pennsylvania State University, more than 30 percent 
of college students in the USA, who seek services for mental health issues, report that they have seriously considered attempting suicide at some point in their lives [14]. Majority of the respondents stated that relationship issues or failure in love life is another reason of suicide cases in Fiji. Many students are engaged in relationships while still studying in the university, and while holding on that relationship, they come across a lot of issues. According to the respondent's perceptions, some students are tortured verbally, and physically abused by their partner. They feel very depressed when their partner cheated, and see suicide as the last option of being heartbroken. Around 60 percent of the respondents answered that the students in Fiji are facing a lot of relationship issues. A few years back in Lautoka, a boy committed suicide because his mother could not afford to take him for shopping. Another incident in Nadi , a 6 yr-old boy committed suicide because of his parents' daily arguments and fighting. The saddest case in Fiji was when one high school working student from Labasa committed suicide, because he failed in passing the external mark rate. Social factors and poor exam results are the main reasons of suicidal thought and actions. Fiji is still facing some challenges in curbing this suicide problem. In 2016, 10 children took their own lives, and 14 children made attempts. Surveys in Fiji have shown that over 90 per cent of people who died by suicide have clinical depression or another diagnosable mental disorder. Substance abuse, like drugs and alcohol, is also linked to suicide. Other possible causes identified during the in-depth interview of the respondents, are cyber-bullying, school, society's expectations and prejudices, and peer pressure. For children, it's the environment at home and school that contributes to their emotional well-being. Unrealistic pressures at home to perform at school can push a child to the brink. Bullying at school could affect the attitude of the children. Unless addressed, it could lead to negative thoughts. The statistics in Fiji revealed an alarming rate of teenage suicide, and should be taken seriously, because there appears to be a trend that needs to be curbed.

\section{The Study of Hipple Identified the Characteristics of the Suicidal Student}

Students contemplating suicide share some common personal characteristics, which include the following feelings [15]:

- Helplessness. This is probably the most common characteristic. The student has been experiencing deep pain, and has been struggling to reduce that pain for some time, but to no avail. $\mathrm{He}$ does not know what else to do. If this is true, then the advisor must be willing to take an active, directive, supportive, and helpful stance.

- Hopeless. Often the pain has been going on for so long with no relief, that the student is ready to give up on everything and everyone. From the student's perspective, there is little reason to live. Reasons to continue to live often require input from an outside resource. As an intervention, the advisor can help rebuild a student's sense of hope for life.

- Confused and having difficulty articulating what is happening. The student knows that something is amiss, but is not able to clearly describe the internal processes taking place. Friends, family, and even instructors may find that this confusion leads to them minimizing the seriousness of the situation $[16,17]$. The advisor can help the student talk through the confusion.

- Perfectionistic. Acute perfectionism can set the stage for the student to see suicide as a viable resolution to pain experienced when his actions, or lack of action, fail to meet high standards. Since little or no action is taking place, the emotional pain continues to grow. Consequently, the advisor has an opportunity to help the student solve the problem, and see alternative or more realistic solutions.

- Isolated. Feeling helpless, hopeless, confused, and idealistic, the student contemplating suicide often has difficulty being with himself or herself, let alone seeing how others might want to be with him or her. It is common for the suicidal student to distance himself or herself from others, thus making it doubly difficult for others to be supportive of him or her. The advisor can assist the student to reach out to others in a more realistic fashion, and consequently re-create a helpful support system.

- Ambivalence. This is a critical characteristic of all individuals who look at suicide as an option. In simple terms, selfinflicted death may be something thought about, planned for, and even attempted $[18,19]$. However, there is also a lifesustaining element in operation for the suicidal; if someone is $100 \%$ suicidal, he would already be dead. It is helpful during conversations to assist the student to talk about both sides of his ambivalence. The suicidal student needs the advisor to not minimize or deny the 'death' side; instead he needs assistance in talking through the reasons to stay alive. One could call this a pro/con discussion of the entire situation. From a practical perspective, conversations are never ended while the student is deeply connected with the 'death' option.

\section{School's Roles in Preventing Suicide Attempts}

Suicides are preventable. All respondents agreed that the school plays important roles in preventing suicide attempts. A student counsellor should have a direct involvement in developing a program that will minimize suicidal attempts. Parent notification and support for student at risk of suicide will be included on the school's roles in preventing suicide attempts. Based on the data gathered, the counsellor plays a major part in preventing the problem. Another way of preventing teenage suicide attempt, establishing a suicide-based suicide prevention program, ranks second. An effective social support within the school campus and individual resilience can help protect the vulnerable persons from suicide by building and improving social connectedness and skills to cope with the difficulties. The teacher will help motivate the student in order to strengthen the student's selfesteem, and build strong communication between teacher-student and parent-children, and help the adolescent in finding their identity in the world.

\section{Conclusion and Recommendation}

Suicide is the most common cause of death among teenagers and youths in Fiji. Student suicides have become an alarming issue in Fiji, since most of the teenagers who commit suicide seems getting younger and younger. Several factors are identified in this study that may lead the student to commit suicide. Students are vulnerable to suicide because of the problems and difficulties they encounter at home and at school. Both parents and school need to understand the potential signs of teenage suicide in order to provide effective prevention programs. The government of Fiji is appealing everyone to address the increasing teenage suicide rate in Fiji.

Based on the finding of the study, the following are recommended:

1. The findings of the study may be included as the bases for the University of Fiji to create a prevention program. There should 
be an open communication between teachers and students to give an opportunity for the student to express his/her feelings or emotions.

2. Parents must be vigilant to their children's unusual behaviour, as well as their relationship with their friends. Parents are encouraged to always communicate with their children to foster a healthy relationship and boost self-esteem.

3. Since the present study utilizes only a limited number of respondents, it is suggested that a wider scope of study is needed to validate the findings.

\section{References}

1. Muehlenkamp JJ, Marrone S, Gray JS, Brown DL (2009) A college suicide prevention model for American Indian students Professional Psychology: Research and Practice 40: 134-140.

2. Grover S, Sarkar S (2004) Suicidal behaviour in adolescents: what can be done? AP J Psychological Medicine Vol. 14 (1).

3. Chatterjee I, Basu J (2000) Perceived Causes of Suicide, Reasons for Living and Suicidal Ideation among Students. Journal of the Indian Academy of Applied Psychology 36: 311-316.

4. Mazza JJ (2000) The relationship between posttraumatic stress symptomatology and suicidal behavior in school-based adolescents. Suicide Life Threat Behav 30(2): $91-103$

5. Dogra AK, Basu S, Das S (2008) Chapter - ii - Shodhganga.

6. Lubin, Gvion Y (2014) Suicide in Israel--an update. Crisis 35: 141-144.
7. Minkoff K (1973) Hopelessness depression and attempted suicide - Research Gate.

8. Reynolds WM, Johnston HF (1988) Handbook of Depression in children and adolescents.

9. Jacob S, Hartshorne TS (2007) Ethics and Law For School Psychologists.

10. Miller DN, Eckert TL (2009) Youth Suicidal Behaviour: An Introduction and Overview 38: 153-167.

11. Creswell JW (2013) Qualitative Inquiry and Research Design.

12. Gines A (1999) General Psychology Rex Bookstore.

13. Lie H (2012) Suicide Behavior among Junior High School Students in Philippines and Indonesia Associated with the social factors. International Journal of BioSciences (JBio), Vol. 2.

14. Novotney A (2014) Students under pressure American Psychological Association.

15. Hippie J (2010) The Role of the Academic Adviser in Preventing Student Suicide NACADA. Clearinghouse of Academic advising Resources.

16. Chatterjee I (2010) Perceived Causes of Suicide Reasons for Living andMedIND.

17. Jacob S, Hartshorne T (2007) Making Ethical Decisions in Challenging Situations-National.

18. ManiamT, Morris P (2000) Suicide in Fiji: A Review of Literature Asia Pacific Journal of Public Health.

19. RichardsonTE, ElliotP, Roberts R, Jansen M (2017) A Longitudinal Study of Financial Difficulties and Mental Health in a National Sample of British Undergraduate Students. Community Mental Health Journal 53: 344-352. 